\title{
Estratégias de aprendizagem: caminhos para o sucesso escolar
}

\author{
Learning strategies: paths to academic success
}

\author{
Luiz Marcelo Darroz ${ }^{1}$ \\ Thais Lorençato Travisan ${ }^{2}$ \\ Cleci Teresinha Werner da Rosa ${ }^{3}$
}

\section{Resumo}

Apresentam-se os resultados de uma investigação que buscou identificar a relação entre as estratégias de aprendizagem dos estudantes e o rendimento acadêmico em Física. Participaram da pesquisa 100 estudantes da terceira série do ensino médio de uma escola da rede privada de ensino em um município do Norte do Rio Grande do Sul. Os participantes da pesquisa foram divididos em dois grupos: os que apresentam facilidade em compreender os conceitos físicos ministrados em aula e os que apresentam dificuldades nesse campo. Como instrumento de coleta de dados, utilizou-se um questionário estruturado na escala de Likert com 35 assertivas relacionadas a cinco categorias de estratégias de aprendizagem. Os dados foram analisados pelas médias obtidas nas respostas dos participantes a cada assertiva do instrumento de coleta de dados e, também, pela média geral de cada categoria de estratégias de aprendizagem. Como resultados, evidenciou-se que os estudantes participantes da pesquisa fazem uso de diferentes estratégias de aprendizagem durante o processo de aprendizagem, com destaque para a utilização de estratégias metacognitivas pelo grupo que apresenta melhor rendimento escolar.

Palavras chave: estratégias de aprendizagem; processo de ensino; ensino de Física

\section{Abstract}

The results hereby presented regard to an investigation that aimed to identify the relationship between the learning strategies of students and the academic performance in Physics. One-hundred students participated in the research conducted in the third year of a private education high school, in a city in the Northern region of the state of Rio Grande do Sul, Brazil. The research participants were divided into two groups: the ones who could easily understand the Physics concepts taught in class and the ones who presented difficulties for the same process. The data collection instrument used was a structured questionnaire in the Likert scale, with 35 affirmatives related to the five learning strategy categories. The data were analyzed by the means obtained from participant responses to each affirmative of the data collection instrument and by the general mean of each learning strategy category. As a result, it was verified that students who participated in the research

\footnotetext{
${ }^{1}$ Universidade Fernando Pessoa | Idarroz@upf.br

${ }^{2}$ Universidade Fernando Pessoa | thais.It128@gmail.com

${ }^{3}$ Universidade Fernando Pessoa | cwerner@upf.br
} 
use different learning strategies during the learning process, highlighting the use of metacognitive strategies by the group presenting better school performance.

Keywords: learning strategies; teaching process; Physics teaching

\section{Introdução}

Atualmente, o Brasil enfrenta problemas em relação ao ensino. Muitos jovens deixam de frequentar as aulas ou de se dedicar à superação dos desafios propostos pelos professores porque a escola não representa um elemento motivador e instigador da sua curiosidade. Segundo Knüppe (2006), a mídia e outros elementos têm sido cada vez mais atrativos, levando a que os alunos cheguem desmotivados à escola, que já não consegue suscitar o seu interesse diante de tantos outros estímulos.

Dentre as várias razões que desmotivam os estudantes em relação ao ensino, está a falta de incentivo e de entendimento das tarefas que Ihes exigem mais, como, por exemplo, as dificuldades de aprendizagem apresentadas na disciplina de Física. Nas palavras de Ivanowski (2005, p. 9):

A Física como instrumento para a compreensão do Universo possui conceitos que se veem presentes no cotidiano das pessoas, e que deveriam tornar o seu entendimento agradável e instigante. No entanto, o que se observa, muitas vezes, é um grande distanciamento entre a realidade vivenciada pelos alunos e aquela apresentada nas salas, o que torna o processo de aprendizagem difícil e desestimulante. Assim, esta Física formal é apresentada antes que os alunos tenham compreendido os fenômenos e processos correspondentes, de modo que não conseguem reconstruí-los e relacioná-los.

Nesse sentido, Caveneghi e Bzuneck (2009) afirmam que os estudantes desmotivados pelas tarefas escolares apresentam um desempenho abaixo de suas reais potencialidades e, consequentemente, distraem-se com facilidade, não participam das aulas, estudam pouco ou nada e distanciam-se do processo de aprendizagem. Assim, não aprendem o suficiente e correm o risco de evadir da escola e de limitar suas oportunidades futuras (CAVENAGHI; BZUNECK, 2009, p. 1479).

Sobre isso, Dutra e Martins (2012, p. 19) enfatizam que, em Física, as dificuldades dos estudantes residem em vários aspectos, dentre os quais estão

[...] a dificuldade em organizar os conteúdos no caderno, em ler e entender os textos usados pelo professor, em representar situações do mundo físico por meio de desenhos e gráficos ou a falta de certa rotina de estudos fora da escola podem interferir bastante no aprendizado. Recuperar esses aspectos pode ser muito difícil, dependendo não somente da escola, do aluno, do professor ou, até mesmo, do método adotado.

Tais dificuldades são acentuadas quando os professores, ao abordar seus conteúdos, não levam em conta as diferenças pessoais dos estudantes e, portanto, consideram que todos aprendem da mesma forma. No entanto, o que se vê na escola é que os professores, no máximo, costumam rotular os estudantes como os que apresentam habilidades para aprender Física e os que não as apresentam. Dificilmente são realizadas atividades que 
possibilitam identificar quais são as suas estratégias de aprendizagem e como elas se relacionam com as necessidades e especificidades da aprendizagem em Física.

A tomada de consciência dos estudantes sobre a forma como aprendem e o que precisam fazer para aprender tem sido apontada, na literatura, como um diferencial entre os alunos considerados bons em Física e os que demonstram dificuldades nessa área (REIF; LARKIN, 1991; MALONE, 2008). Dessa forma, uma das potencialidades didática do professor poderia ficar mais atento e vigilante à forma com os alunos aprendem e a partir disso oportunizar situações que Ihes sejam favorecedoras da aprendizagem. Em outras palavras, isso está relacionado com a identificação das estratégias de aprendizagem empregada por cada um no momento de aprender.

O exposto remete ao problema central deste estudo que foi circunstanciado pelo seguinte questionamento: quais as estratégias de aprendizagem empregada pelos estudantes com bom rendimento escolar e de que forma elas se diferenciam das utilizadas por aqueles que apresentam dificuldades na aprendizagem de Física?

Dessa forma, o presente artigo tem por objetivo apresentar os resultados de uma pesquisa que buscou investigar a relação entre as estratégias de aprendizagem dos estudantes e o rendimento acadêmico em Física. Tal investigação justifica-se pelo fato de que mapear essas estratégias de aprendizagem, de modo a identificar características específicas para cada classe de estudante (com bom rendimento cognitivo versus com dificuldades na compreensão), pode contribuir para a qualificação do processo de ensino e aprendizagem em Física, uma vez que, no campo da aprendizagem, a identificação de como o aluno aprende e do que ele pode fazer para melhorar sua aprendizagem é considerada um aspecto fundamental para o êxito nessa disciplina (ROSA, 2014). Além disso, conhecendo-as, os professores podem servir-se dessas características e buscar metodologias que favoreçam a aprendizagem.

\section{Revisão de literatura}

As estratégias de aprendizagem são um assunto constantemente presente nas pesquisas educacionais da atualidade. Dentre as investigações, o foco tem sido a preocupação com a qualidade da aprendizagem dos estudantes; isto é, como tornar o aluno um agente ativo de seu próprio processo de aprendizagem. Nesse sentido, pesquisadores como Boruchovitch (2007), Portilho (2003), Dembo (1994), Garner e Alexandrer (1989), Martins e Zerbini (2014), entre outros, apontam que, dentre os fatores que mais corroboram para a melhora na qualidade do processo de ensino, estão a escolha de estratégias de aprendizagem capazes de contemplar os diferentes estilos de aprendizagens dos estudantes inseridos no ambiente escolar e a identificação, por parte do aluno, da forma como ele aprende.

Warr e Allan (1998), por sua vez, acreditam que a dificuldade de cada situação de ensino exige um tipo diferente de estratégia de aprendizagem. Diante disso, os autores classificam os tipos de estratégia em Estratégia Cognitiva, Estratégia Comportamental e Estratégia Autorregulatória. Por sua vez, Dembo (1994) e Beltrán (1994), Garner e Alexandre (1989), autores que dedicam seus estudos à compreensão da forma como os estudantes aprendem, dividem as estratégias de aprendizagem em Cognitiva e Metacognitiva.

Dessa forma, as estratégias de aprendizagem classificadas a partir dos trabalhos de Warr e Allan (1998), Dembo (1994), Martins e Zerbini (2014) abrem um amplo espectro de 
possibilidades para superar os desafios de ensinar e aprender, abrangendo, significativamente, diversos caminhos pelos quais se dá a construção do conhecimento. Por esse motivo, é possível unir tais pensamentos e gerar um leque de estratégias de aprendizagem diversas, traçadas pelos estudantes, a fim de promover avanços cognitivos. A partir dos trabalhos desses autores, foi elaborado para a presente investigação um instrumento para identificar as estratégias de aprendizagem adotada pela mostra selecionado para o estudo. Esse instrumento elaborado a partir dos referenciais citados apresentou cinco categorias de estratégias de aprendizagem.

A primeira associada a "Estratégia Controle de Emoção" que está ligada ao aspecto psicológico do estudante e, portanto, direcionada ao seu emocional e ao controle da forma como as emoções serão expressas (GROSS, 2013). Desse modo, ela é apresentada quando o sujeito está diante de um desafio que pode ocasionar descontrole emocional e grandes níveis de estresse, prejudicando suas associações mentais.

Para Assman (1998), o conhecimento humano nunca depende apenas de operações mentais, pois toda atividade que envolva a inteligência está conectada às emoções. Sendo assim, é uma estratégia de importância relevante no processo de aprendizagem, pois evidentemente o estudante apresentará grandes dificuldades ao aprender em desequilíbrio psicológico, diferentemente do que ocorreria se estivesse calmo e despreocupado com problemas além dos conteúdos escolares. Sobre isso, Fonseca (2016, p. 366) afirma que:
As emoções no seu aspecto mais abrangente encerram, em paralelo, aspectos comportamentais positivos e negativos, conscientes e inconscientes, e podem equivaler semanticamente a outras expressões, como a afetividade, a inteligência interpessoal, a inteligência emocional; a cognição social; a motivação, a conotação, o temperamento e a personalidade do indivíduo.

Com a mesma importância no processo de aprender, tem-se a segunda estratégia de aprendizagem utilizada no estudo, a denominada "Estratégia Autorregulatória", que está ligada à busca da compreensão do automonitoramento do estudante durante as aulas, à sua motivação para a aprendizagem, aos esforços para compreender e, também, ao controle sobre situações que podem desviar sua atenção (ABBAD et al., 2012). Um exemplo comum da Estratégia Autorregulatória é o esforço que os alunos fazem ao permanecer prestando atenção em uma aula que não julgam atrativa ou interessante.

A terceira estratégia denominada "Estratégia de Busca de Ajuda Interpessoal" está associada ao que Zerbini e Abbad (2008) inferem como a mobilização do estudante em procurar a ajuda de um colega e/ou professor quando não consegue compreender completamente o tema estudado. Isso representa um comportamento proativo do aprendiz, ao buscar recursos alternativos com outras pessoas para que sua aprendizagem seja concluída. Assim, essas estratégias podem apresentar influência direta no desempenho dos estudantes, uma vez que, em algumas situações de ensino, eles ficam tímidos ao perceber que não compreenderam o conteúdo com apenas algumas explicações e não recorrem a essa estratégia para concluir o processo de aprendizagem.

Por fim, identifica-se as estratégias apontadas por Boruchovitch (2007) como "Estratégias Cognitiva e Metacognitiva". Segundo a autora: 
[...] as intervenções do tipo cognitivo são voltadas para o trabalho com uma ou mais estratégias de aprendizagem específicas (sublinhar, anotar). As do tipo metacognitivo são orientadas para apoiar os processos executivos de controle, como o planejamento, o monitoramento e a regulação dos processos cognitivos e do comportamento, já que o aumento do conhecimento metacognitivo vem sendo pensado como uma forma de se desenvolver o controle executivo (p. 158).

Dessa forma, a Estratégia Cognitiva está relacionada à execução de tarefas que promovem o conhecimento, como, por exemplo, realizar resumos sobre os conteúdos ou fazer anotações durantes as aulas. Ela é uma das estratégias mais comuns quando se trata de se apropriar do conhecimento através da organização e da memória. Porém, na maioria das vezes, o estudante faz uso dessa estratégia mecanicamente. Para Dembo (1994), ela está associada a ações e pensamentos capazes de facilitar a memorização e a armazenagem de informações, como organizar, sublinhar, resumir, entre outras similares.

A Estratégia Metacognitiva, por sua vez, está relacionada ao aprender a aprender, representando aquelas ações às quais os estudantes recorrem quando se recordam de que forma aprenderam melhor um determinado conteúdo. Ou seja, elas estão presentes quando o sujeito identifica qual a melhor maneira de resolver a situação-problema proposta. Para Rosa (2011), os estudantes que recorrem com mais frequência a estratégias metacognitivas tendem a ter melhor rendimento escolar na disciplina em que essa estratégia ocorre.

Apesar de estarem próximas das estratégias autorregulatórias, as de natureza metacognitiva se diferenciam por envolverem um conjunto maior de elementos, como os vinculados ao conhecimento metacognitivo. Esses, por sua vez, estão associados aos conhecimentos das variáveis pessoa, tarefa e estratégia e permitem a identificação da forma como o sujeito se reconhece diante da situação apresentada (RIBEIRO, 2003; ROSA, 2011).

Um exemplo dessas Estratégia Metacognitiva consiste na elaboração de desenhos para compreender o fenômeno físico contido em uma situação de Física proposta por um problema, ou, ainda, na elaboração de um julgamento pelo estudante sobre o modo como ele precisa se portar para acompanhar uma determinada explicação do professor (TAASOOBSHIRAZI; FARLEY, 2013)

Com relação a utilização da metacognição como recurso de aprendizagem Rosa (2011) considera que ela por ser entendida como tomada de consciência do sujeito sobre seus conhecimentos, sobre seu modo de pensar, favorece a regulação de suas ações, o que no âmbito educacional é particularmente interessante. Nas palavras da autora a metacognição tem a sua potencialidade para a aprendizagem residindo

no fato de que promove nos estudantes um pensar sobre seus conhecimentos, oferecendo-lhes condições de controlar a execução de suas ações como se um supervisor monitorasse seus pensamentos. Os estudantes, ao pensarem ativamente sobre o que estão fazendo, são capazes de exercer um controle sobre seus processos mentais e, assim, obter ganhos cognitivos (p.30).

O conhecimento sobre as estratégias de aprendizagem rende ao estudante um melhor desempenho escolar e uma possibilidade maior de êxito ao enfrentar dificuldades diversas (Silva \& Sá, 1997). Logo, as estratégias funcionam como um apoio à aprendizagem, pois é 
através delas que os alunos encontram os melhores caminhos para efetivamente obter conhecimento.

Direcionando-se a essa linha de reflexão, é necessário que o professor estimule seus educandos a desenvolver suas habilidades da maneira que thes for mais adequada para ampliar o rendimento escolar. Nessa perspectiva, Boruchovitch (2014, p. 402) recomenda que se ultrapasse o caráter remediativo dessas intervenções, caminhando rumo a um enfoque preventivo, que institua a autorregulação da aprendizagem, o aprender a aprender e o desenvolvimento metacognitivo como pontos fundamentais dos projetos psicopedagógicos das escolas.

Disso posto, retoma-se o questionamento central reforçando a necessidade de identificar que tipo de estratégia de aprendizagem, frente as apresentadas nessa revisão de literatura, são acionadas pelos estudantes durante a aprendizagem em Física e se há distinção entre as utilizadas por aqueles que apresentam bons rendimentos na disciplina e os que se mostram com dificuldades de aprendizagem nessa disciplina.

\section{Metodologia de pesquisa}

O grupo que constituiu o rol de participantes deste estudo foi composto por 100 estudantes da terceira série do ensino médio de uma escola da rede privada de ensino de um município do Norte do Rio Grande do Sul. A opção por realizar a pesquisa junto a esse grupo se deveu ao fato de a escola dividir o ano letivo em trimestres e possuir em sua matriz curricular quatro horas aula semanais de Física ministradas pelo mesmo professor, bem como porque seu sistema avaliativo de aprendizagem se expressa através de notas e, no decorrer dos trimestres, é aplicado um instrumento de avaliação que exige dos estudantes a capacidade de resolver problemas envolvendo conceitos físicos. Frente a esse contexto, considera-se que os sujeitos do estudo estão expostos a um mesmo sistema, incluindo os mesmos conteúdos, mesmo professor e sistema de avaliação, o que leva a pressupor que as diferenças na aprendizagem estão mais vinculadas a questões pessoais, como as estratégias empregadas por cada um na aprendizagem.

Com relação aos aspectos didático-metodológicos utilizados pelo professor cabe ressaltar que não foi o foco do estudo, mas que em linhas gerias é possível descrever que suas aulas são expositivas e dialogadas. Além disso, faz uso de um livro didático de referência e utilizado pelos alunos no decorrer da aula, bem como recorre ao uso de tecnologias digitais como softwares e simulações e realiza atividades experimentais.

Para o estudo, os sujeitos foram divididos em dois grupos, a fim de diferenciar as estratégias de aprendizagem adotadas por eles: um grupo constituído pelos que apresentam bom rendimento escolar, caracterizado pela facilidade na resolução e interpretação de problemas em Física; e, o segundo grupo por aquele que em oposição ao primeiro grupo, apresentam dificuldades em Física, caracterizado pelo baixo rendimento escolar na disciplina. O primeiro grupo constituiu-se de 39 estudantes que, no decorrer do ano letivo de 2017, apresentaram notas superiores à média da escola (60\%) e que, na opinião do professor, demonstram facilidade em Física. Os demais, 61 alunos, compuseram o segundo grupo.

Como mencionado na seção anterior, para a coleta de dados, utilizou-se um instrumento elaborado a partir dos estudos de Martins e Zerbini (2014), relacionando Estratégia Controle de Emoção, Estratégia Busca de Ajuda Interpessoal, Estratégia 
Autorregulatória e Estratégia Cognitiva. A esse instrumento adaptado desses estudos, forma incluídas as Estratégia Metacognitiva, seguindo estudos como os desenvolvidos por Weinstein e Mayer (1986), Flavell, Miller e Miller (1999) e Rosa (2014).

Esse instrumento, estruturado na escala de Likert, é composto de 35 assertivas fechadas que buscam identificar as estratégias de aprendizagem mais recorrentes em cada grupo de estudantes. Cada uma das assertivas apresenta características correspondentes a uma estratégia de aprendizagem, e por esse motivo elas estão divididas em cinco categorias: Estratégia Controle de Emoção, Estratégia Autorregulatória, Estratégia Busca de Ajuda Interpessoal, Estratégia Cognitiva e Estratégia Metacognitiva.

Dessa forma, cada uma das afirmações possibilitava aos participantes a escolha da opção que, em seu julgamento, melhor representaria suas estratégias de aprendizagem frente a uma determinada situação de ensino. Assim, os participantes deveriam marcar 1, se nunca utilizam a estratégia contida na assertiva; 2 , se a estratégia quase nunca é utilizada; 3, se às vezes recorrem à estratégia de ensino para resolver a situação apresentada; 4, se quase sempre utilizam a respectiva estratégia; ou 5, se sempre fazem uso da estratégia de aprendizagem. Cabe mencionar que as assertivas foram dispostas aleatoriamente no instrumento, a fim de evitar a indução das respostas durante a escolha das alternativas.

O Quadro 1 contém as assertivas relacionadas à Estratégia Controle de Emoção. Esse grupo de afirmações busca perceber o controle das emoções dos participantes frente às situações de ensino.

Quadro 1 - Assertivas que apresentam características da Estratégia Controle de Emoção

\begin{tabular}{|c|c|}
\hline$\#$ & Assertiva \\
\hline 1 & Mantive calma quando tive dificuldades nos conteúdos de Física. \\
\hline 6 & Repeti a mim mesmo, quando ansioso, que tudo sairia bem ao final da disciplina. \\
\hline 11 & Mantive calma com a possibilidade de ter um rendimento abaixo do esperado em Física. \\
\hline 16 & Mantive calma diante dos erros que cometi ao realizar atividades de Física. \\
\hline 21 & Durante as aulas de Física estava calmo e tranquilo para ouvir as explicações do professor. \\
\hline 26 & Fiquei irritado ao perceber que não compreendi o conteúdo. \\
\hline 31 & Fiquei irritado ou ansioso ao perceber que não tive bom rendimento em alguma avaliação. \\
\hline
\end{tabular}

O Quadro 2 apresenta as afirmações vinculadas às características da Estratégia Autorregulatória, a qual evidencia o poder de superação dos estudantes participantes da pesquisa ao se depararem com uma situação desconfortável no decorrer do processo de ensino, bem como as atitudes individuais/próprias que facilitam a busca por conhecimento.

No Quadro 3, estão listadas as assertivas que buscam evidenciar as ações a que os estudantes recorrem quando necessitam de ajuda de outra pessoa para compreender o conteúdo. Essas são as assertivas relacionadas à Estratégia Busca de Ajuda Interpessoal. 
Quadro 2 - Assertivas que apresentam características da Estratégia Autorregulatória

\begin{tabular}{|c|c|}
\hline$\#$ & Assertiva \\
\hline 2 & Esforcei-me mais quando percebi que estava perdendo a concentração nas aulas. \\
\hline 7 & Forcei-me a manter a atenção nos estudos quando me senti desinteressado. \\
\hline 12 & Esforcei-me mais quando percebi que estava perdendo interesse no assunto. \\
\hline 17 & Revisei a matéria para verificar o quanto eu dominava o conteúdo. \\
\hline 22 & Esforcei-me para verificar minha compreensão sobre o que estava sendo ensinado. \\
\hline 32 & Busquei compreender melhor o conteúdo ao estudar na apostila da escola. \\
\hline
\end{tabular}

Quadro 3 - Assertivas que apresentam características da Estratégia Busca de Ajuda Interpessoal

\begin{tabular}{|c|c|}
\hline$\#$ & Assertiva \\
\hline 3 & Busquei auxílio do professor para esclarecer minhas dúvidas sobre o conteúdo. \\
\hline 8 & Busquei auxílio de colegas durante as aulas para esclarecer minhas dúvidas sobre o conteúdo. \\
\hline 13 & Troquei mensagens com os colegas para esclarecer dúvidas sobre o conteúdo. \\
\hline 18 & Busquei aulas particulares com outro professor. \\
\hline 23 & Procurei por outras pessoas que já tiveram os conteúdos de Física para tirar dúvidas. \\
\hline 28 & Procurei me reunir em grupo com colegas, fora da sala de aula, para entender o conteúdo. \\
\hline 33 & Criei um grupo em redes sociais com colegas para trocar ideias sobre os conteúdos. \\
\hline
\end{tabular}

Quadro 4 - Assertivas que apresentam características da Estratégia Cognitiva

\begin{tabular}{|c|c|}
\hline$\#$ & Assertiva \\
\hline 4 & Revisei os conteúdos relativos aos exercícios em que cometi erros. \\
\hline 9 & Fiz anotações e resumos sobre os conteúdos de Física. \\
\hline 14 & Li os conteúdos várias vezes como método para aprender. \\
\hline 19 & Fiz esquemas dos conteúdos de Física como método para aprender. \\
\hline 24 & Associei os conteúdos de Física aos meus conhecimentos anteriores. \\
\hline 34 & $\begin{array}{r}\text { Diferenciei, ao analisar os conteúdos de Física, os aspectos mais importantes dos menos } \\
\text { importantes. }\end{array}$ \\
\hline
\end{tabular}


A Estratégia Cognitiva está associada às ações das quais os alunos se apropriam na busca de conhecimento. Nesse sentido, o Quadro 4 reúne as assertivas que têm essa estratégia como característica.

A última estratégia de aprendizagem desta investigação denomina-se Estratégia Metacognitiva e está relacionada ao pensamento a que o aluno recorre para buscar as formas que melhor aprende para resolver situações. No Quadro 5, apresentam-se as assertivas associadas a essa estratégia.

Quadro 5 - Assertivas que apresentam características da Estratégia Metacognitiva

\begin{tabular}{|c|c|}
\hline \# & Assertiva \\
\hline 5 & $\begin{array}{l}\text { Na resolução de problemas de Física, procuro desenhar o fenômeno presente nas questões para } \\
\text { auxiliar na visualização do evento. }\end{array}$ \\
\hline 10 & Geralmente, explico para os demais colegas o conteúdo abordado nas aulas de Física. \\
\hline 15 & Compreendo quais são os meios que facilitam a minha aprendizagem. Ex: ler, escrever, sublinhar, etc. \\
\hline 20 & Durante uma prova, leio as questões e consigo identificar qual é a melhor estratégia para resolvê-la. \\
\hline 25 & $\begin{array}{l}\text { Durante provas e atividades, tento recorrer a meus conhecimentos adquiridos antes de buscar ajuda } \\
\text { no material. }\end{array}$ \\
\hline 30 & Após uma atividade experimental, consigo explicar o que realizei e qual foi o objetivo da atividade. \\
\hline 35 & $\begin{array}{c}\text { Quando não compreendo o conteúdo explicado pelo professor, consigo traçar estratégias para } \\
\text { aprender de outras formas. }\end{array}$ \\
\hline
\end{tabular}

Dessa forma, a pesquisa assume o caráter quali-quantitativo, pois, embora o desempenho escolar dos estudantes e a análise dos resultados necessitem da sistematização de informações numéricas, também foi considerada a opinião do professor em relação aos estudantes que apresentam dificuldades no conteúdo e aos que não apresentam. Gil (2002, p. 134) assim elucida os dois tipos de pesquisa em questão:

Nas pesquisas quantitativas, as categorias são frequentemente estabelecidas a priori, o que simplifica sobremaneira o trabalho analítico. Já nas pesquisas qualitativas, o conjunto inicial de categorias em geral é reexaminado e modificado sucessivamente, com vista a obter ideais mais abrangentes e significativos. Por outro lado, nessas pesquisas os dados costumam ser organizados em tabelas, enquanto, nas pesquisas qualitativas, necessita-se valer de textos narrativos, matrizes, esquemas etc.

Ainda, a pesquisa se caracteriza como investigação social e exploratória, uma vez que busca verificar os métodos de aprendizagem dos estudantes de Física. Segundo Gil (2008, p. 27), esse tipo de investigação "têm como principal finalidade desenvolver, esclarecer e modificar conceitos e ideias, tendo em vista a formulação de problemas mais precisos ou hipóteses pesquisáveis para estudos posteriores".

Para a análise dos resultados, após a aplicação do instrumento de coleta de dados, organizaram-se duas tabelas, uma para cada grupo de estudantes. Esses resultados serão 
apresentados e discutidos no próximo item, tendo como base as médias das respostas de cada categoria e a comparação entre as médias dos Grupos 1 e 2.

\section{Apresentação e discussão dos resultados alcançados}

Buscando identificar as estratégias de aprendizagem mais recorrentes em cada grupo de estudantes participantes da pesquisa, atribuiu-se uma pontuação para cada valor assinalado na escala. Essa pontuação considerou a seguinte padronização: adicionou-se 1 ponto para a opção "nunca"; 2 pontos para a opção "quase nunca"; 3 pontos para a opção "às vezes"; 4 pontos para a opção "quase sempre"; e 5 pontos para a opção "sempre". Porém, para as assertivas 26 e 31, referentes à categoria Estratégia Controle de Emoção, foi necessário realizar uma inversão na pontuação atribuída, pois tais sentenças ressaltam ações que se opõem às características da estratégia. Isto é, por serem atitudes que desestimulam o controle emocional do estudante, passou-se a atribuir 5 pontos para a resposta "nunca"; 4 pontos para "quase nunca"; 3 pontos para "às vezes"; 2 pontos para "quase sempre"; e 1 ponto para a resposta "sempre".

Por meio dessa pontuação, analisaram-se os dados para identificar a estratégia de aprendizagem mais utilizada pelos componentes de cada grupo. Mediante a tabulação dos dados obtidos de cada participante em relação às 35 assertivas, obteve-se a média geral da recorrência de cada tipo de estratégia, bem como a afirmativa que mais se destacou. Quanto mais próximo de cinco estivesse a média geral de cada assertiva, maior a frequência de utilização da ação estabelecida na assertiva. Da mesma forma, quanto mais próxima de cinco estivesse a média geral das pontuações obtidas para o conjunto de assertivas de uma dada estratégia de aprendizagem, maior a recorrência dessa estratégia no decorrer do processo de ensino de Física.

A Estratégia Controle de Emoção relaciona-se ao temperamento, à afetividade, às interações sociais e à personalidade do sujeito, sendo de fundamental importância no processo de aprender (Fonseca, 2016). Esse processo está ligado a diversos fatores que influenciam positiva ou negativamente o estudante, sendo um deles a emoção. Dessa forma, se o estudante estiver abalado emocionalmente, suas capacidades cognitivas podem ser afetadas.

Segundo Assmann (1998), o conhecimento nunca anda só, e a inteligência depende do estado emocional do indivíduo. Buscando perceber essas características nos dois grupos investigados, tabularam-se os dados e estabeleceram-se as médias. Os resultados encontram-se dispostos na Tabela 1.

A análise dos dados obtidos na categoria Estratégia Controle de Emoção indica uma diferença de 0,02 entre as médias gerais. Tais resultados demonstram que os dois grupos pesquisados apresentam uma pontuação semelhante para as características referentes a essa estratégia de aprendizagem, pois procuram manter a calma na maioria das vezes em que se encontram em estados de possível estresse, raiva ou nervosismo.

Conforme os resultados referentes ao Grupo 1, a assertiva com maior média é a 21, o que indica que esse grupo de sujeitos julga se manter calmo e atento durante as aulas. Segundo Fonseca (2016), esses elementos são extremamente importantes no processo de aprendizagem e proporcionam um bom rendimento durante a obtenção de conhecimentos. Já entre os estudantes do Grupo 2, a assertiva 16 é a mais recorrente e está relacionada com a calma perante erros cometidos durante atividades nas aulas de Física. 
Tabela 1 - Médias para as assertivas correspondentes à Estratégia Controle de Emoção

\begin{tabular}{c|c|c}
\hline $\begin{array}{c}N^{0} \text { da } \\
\text { assertiva }\end{array}$ & $\begin{array}{c}\text { Média das respostas dos } \\
\text { participantes do Grupo 1 }\end{array}$ & $\begin{array}{c}\text { Média das respostas dos } \\
\text { participantes do Grupo 2 }\end{array}$ \\
\hline 1 & 3,67 & 3,41 \\
\hline 6 & 3,31 & 2,93 \\
\hline 11 & 3,18 & 3,38 \\
\hline 16 & 3,67 & 3,67 \\
\hline 21 & 3,97 & 3,51 \\
\hline 26 & 2,72 & 3,38 \\
\hline 31 & 2,74 & 2,84 \\
\hline Média geral & 3,32 & 3,30 \\
\hline
\end{tabular}

Tal resultado permite concluir que os estudantes que apresentam um rendimento abaixo do esperado, na maioria das vezes, encaram com calma os erros cometidos. Embora esse aspecto possa ser considerado positivo, uma vez que é errando que se aprende e que é mantendo a calma que se proporciona maior entendimento acerca dos erros cometidos, também pode significar falta de preocupação dos estudantes quando não compreendem os conteúdos estudados.

A Estratégia Autorregulatória é a que demanda a motivação do estudante para realizar diferentes tarefas, bem como o seu esforço para monitorar a própria compreensão. Essa é a estratégia que depende diretamente do sujeito para enfrentar com persistência situações que the dispersem a atenção e exijam esforços para obter conhecimento (ABBAD et al., 2012). Trata-se, portanto, de uma estratégia importante para o processo de ensinoaprendizagem, pois o professor não consegue mediar o conhecimento com um aluno que não está motivado a aprender. A Tabela 2 apresenta os resultados obtidos nas assertivas correspondentes à Estratégia Autorregulatória.

Tabela 2 - Médias para as assertivas correspondentes à Estratégia Autorregulatória

\begin{tabular}{c|c|c}
\hline $\begin{array}{c}\mathrm{N}^{0} \text { da } \\
\text { assertiva }\end{array}$ & $\begin{array}{c}\text { Média das respostas dos } \\
\text { participantes do Grupo 1 }\end{array}$ & $\begin{array}{c}\text { Média das respostas dos } \\
\text { participantes do Grupo 2 }\end{array}$ \\
\hline 2 & 3,76 & 3,21 \\
\hline 7 & 3,87 & 3,06 \\
\hline 12 & 3,51 & 3,14 \\
\hline 17 & 3,43 & 2,83 \\
\hline 22 & 3,94 & 3,44 \\
\hline 27 & 3,30 & 3 \\
\hline 32 & 3,20 & 2,75 \\
\hline Média geral & 3,57 & 3,06 \\
\hline
\end{tabular}

Os resultados contidos na Tabela 2 demonstram uma diferença de 0,51 entre as médias dos grupos, dado que indica que os estudantes que constituíram o Grupo 1 dedicam-se mais ao monitoramento de sua compreensão acerca dos conteúdos de Física estudados. Embora as respostas dos participantes do Grupo 2 apresentem menor média geral, percebe-se, pelas médias obtidas em cada uma das assertivas, que esses sujeitos também recorrem a esse tipo de estratégia durante o processo de aprendizagem. Por sua vez, a assertiva com maior média entre componentes do Grupo 1 é a 22, que retrata o esforço do estudante em verificar se está aprendendo o que é ensinado e que indica maior 
preocupação em entender a fala do professor. Para os sujeitos do Grupo 2, a afirmação com maior média é a 17. Esse resultado evidencia que os estudantes realizam tarefas também fora da sala de aula com motivação para aprender, porém, como seu rendimento não é satisfatório, talvez o façam apenas quando necessitam estudar para uma avaliação.

Uma ação proativa do estudante na busca por conhecimento através da ajuda de outros para concluir sua aprendizagem caracteriza a Estratégia Busca de Ajuda Interpessoal. Conforme Zerbini e Abbad (2008), esse tipo de estratégia é evidenciado quando o estudante procura por um professor ou colega para esclarecer suas dúvidas ou entender algo que ainda não lhe faz sentido. Entretanto, essa é uma estratégia que requer esforço do estudante, pois algumas vezes ele se sente tímido ao precisar de auxílio de outras pessoas e não consegue concluir seu processo de busca de informações. Os resultados obtidos para as assertivas dessa estratégia estão sistematizados na Tabela 3.

Tabela 3 - Médias para as assertivas correspondentes à Estratégia Busca de Ajuda Interpessoal

\begin{tabular}{c|c|c}
\hline No da assertiva & $\begin{array}{c}\text { Média das respostas dos } \\
\text { participantes do Grupo 1 }\end{array}$ & $\begin{array}{c}\text { Média das respostas dos } \\
\text { participantes do Grupo 2 }\end{array}$ \\
\hline 3 & 3,74 & 2,88 \\
\hline 8 & 3,46 & 3,40 \\
\hline 13 & 2,33 & 2,75 \\
\hline 18 & 1,25 & 1,47 \\
\hline 23 & 2,02 & 2,13 \\
\hline 28 & 1,51 & 1,98 \\
\hline 33 & 1,23 & 1,52 \\
\hline Média geral & 2,22 & 2,30 \\
\hline
\end{tabular}

A análise dos resultados contidos na Tabela 3 demonstra que os participantes do Grupo 2 utilizam mais a Estratégia Busca de Ajuda Interpessoal do que os do Grupo 1. No entanto, a diferença apresentada entre as médias dos grupos $(0,08)$ não é expressiva. Além disso, esses dados apontam que os participantes, tanto do Grupo 1 quanto do Grupo 2, apresentam dificuldades para buscar ajuda de outros para aprender, talvez por comodidade ou timidez. Quando há necessidade de interagir com os demais colegas e com os professores sobre os conteúdos de Física, os alunos não o fazem, muitas vezes permanecendo com dificuldades na compreensão de alguns conceitos.

Em relação às respostas dadas pelos componentes do Grupo 2, a assertiva 8 é a que apresenta maior média, ou seja, esses estudantes afirmam buscar ajuda dos colegas quando enfrentam dificuldades nos assuntos abordados. Por sua vez, as respostas do Grupo 1 revelam duas assertivas com médias superiores a três pontos (assertivas 3 e 8). Esses resultados indicam que os estudantes com bom aproveitamento escolar buscam sanar suas dúvidas com o auxílio do professor, apontando a importância de manter bom relacionamento com o docente, buscar fontes seguras, não ter timidez para expor que ainda não aprendeu determinado conceito e interagir com os colegas na tentativa de compreendê-lo. Os índices podem representar uma característica da forma com as aulas são conduzidas ou até mesmo características pessoais e metodológicas do professor. Entretanto, a análise mais detalhada dessa relação entre as características da ação didática e o modo como ela reflete na aprendizagem dos alunos, foge ao escopo desse texto e está sendo tema de discussão de outros estudos. Porém os dados aqui apresentados 
corroboram a pertinência desse novo estudo, como tem sido assinalado por Monereo (2001) em relação a potencialidade de um professor que utiliza em sua aprendizagem e em seu processo de ensino estratégias metacognitivas e que, por consequência, induzem os alunos a utilizá-las também.

A Tabela 4 apresenta as médias das assertivas relacionadas à Estratégia Cognitiva, que dizem respeito às ações que os estudantes realizam quando estão dispostos a aprender, como sublinhar, sintetizar, esquematizar, etc. (BORUCHOVITCH, 2007; DEMBO, 1994). Tais aspectos se revelam importantes na aprendizagem, uma vez que estão relacionadas a movimentos cognitivos que podem resultar na qualificação da aprendizagem. Reler o que foi discutido em aula, estabelecer relações com situações cotidianas, fazer esquemas, buscar associações, são aspectos associados a "comportamentos e pensamentos que o sujeito pode utilizar no decurso da aprendizagem e que influenciam a forma como processa a informação" (FIGUEIRA, 2006, p. 7). Pozo (1999), por sua vez, ressalta que as estratégias de aprendizagem são sistemas conscientes de decisões mediadas por sistemas simbólicos e que essas se diferenciam do uso de técnicas, porque são deliberadamente selecionadas pelo sujeito a fim de atingir um objetivo de natureza cognitiva. Nesse contexto, as estratégias cognitivas estariam focadas a lograr êxito na aquisição de uma informação e não reduzidas a mera memorização de informações.

Tabela 4 - Médias para as assertivas correspondentes à Estratégia Cognitiva

\begin{tabular}{c|c|c}
\hline$N^{\circ}$ da assertiva & $\begin{array}{c}\text { Média das respostas dos } \\
\text { participantes do Grupo 1 }\end{array}$ & $\begin{array}{c}\text { Média das respostas dos } \\
\text { participantes do Grupo 2 }\end{array}$ \\
\hline 4 & 3,02 & 2,55 \\
\hline 9 & 4,07 & 3,73 \\
\hline 14 & 2,79 & 2,70 \\
\hline 19 & 4 & 3,32 \\
\hline 24 & 3,12 & 3 \\
\hline 29 & 3,18 & 3,06 \\
\hline 34 & 3,79 & 3,06 \\
\hline Média geral & 3,42 & 3,06 \\
\hline
\end{tabular}

Fonte: dados da pesquisa, 2017

Com base nos resultados das médias gerais obtidas, nota-se uma diferença de 0,36 pontos entre os dois grupos, destacando-se as respostas do Grupo 1. Tais resultados indicam que esses estudantes tomam mais atitudes cognitivas, como a realização de atividades de organização, memória e revisão, as quais tornam seu desempenho mais satisfatório nas aulas de Física em comparação com o Grupo 2. Os dois grupos inferem em maior média a assertiva 9, demonstrando que, apesar de usarem esse tipo de estratégia de aprendizagem com frequências diferentes, anotam e resumem os conteúdos de Física com maior assiduidade.

Por fim, a Estratégia Metacognitiva compreende as estratégias do pensamento, do aprender a aprender, na qual o aluno, para resolver problemas, faz associações entre as formas como melhor aprende. A Estratégia Metacognitiva parte da metacognição, que consiste na tomada de consciência do estudante sobre seu modo de pensar, ou seja, no monitoramento de suas ações (FLAVELL; MILLER; MILLER, 1999; ROSA, 2014). Na Tabela 5 , encontram-se os resultados das médias obtidas no estudo em relação a essas estratégias de aprendizagem. 
Tabela 5 - Médias para as assertivas correspondentes à Estratégia Metacognitiva

\begin{tabular}{c|c|c}
\hline No da assertiva $^{*}$ & $\begin{array}{c}\text { Média das respostas dos } \\
\text { participantes do Grupo 1 }\end{array}$ & $\begin{array}{c}\text { Média das respostas dos } \\
\text { participantes do Grupo 2 }\end{array}$ \\
\hline 5 & 3,64 & 3,08 \\
\hline 10 & 2,79 & 1,83 \\
\hline 15 & 4,48 & 4,03 \\
\hline 20 & 3,61 & 3,03 \\
\hline 25 & 3,79 & 3,34 \\
\hline 30 & 3,64 & 3,37 \\
\hline 35 & 3,71 & 2,93 \\
\hline Média geral & 3,67 & 3,08 \\
\hline
\end{tabular}

Fonte: dados da pesquisa, 2017.

Segundo os dados apresentados na Tabela 5, existe uma divergência notável, expressa pela diferença de 0,58 pontos, entre as médias das respostas do Grupo 1 e as do Grupo 2. Além disso, em todas as assertivas que relacionam características metacognitivas, os estudantes do Grupo 1 apresentam médias superiores às do Grupo 2. Isso significa que o grupo de estudantes com melhor desempenho escolar utiliza com maior frequência as estratégias do pensamento.

Torna-se importante destacar que conforme assinalado por Flavell, Miller e Miller (1999) não há uma distinção clara entre as estratégias cognitivas e as metacognitivas ou que na prática torna-se fácil identificar se a estratégia que o sujeito está utilizando é de natureza cognitiva ou metacognitiva. Muitas vezes elas se mesclam e podem em determinados casos estar servindo a questões cognitivas e em outra as metacognitivas. Flavell (1979) menciona que por vezes ao utilizar uma estratégia cognitiva, questionando a si mesmo sobre um determinado conteúdo com intuito de verificar os próprios conhecimentos, pode-se avaliar - que se sabe sobre um determinado assunto e isso está associado a estratégia metacognitiva. Ao mesmo tempo, o autor observa que é possível, em determinados casos, que a mesma estratégia seja evocada para atender a uma ou a outra finalidade (cognitiva ou metacognitiva), ou não atingir nenhum dos objetivos. Portanto, as estratégias podem operar em diferentes contextos, o que reforça a sua importância na aprendizagem.

Em síntese, os resultados desta investigação indicam que os participantes da pesquisa obtiveram médias gerais superiores em quatro das cinco categorias estabelecidas, dados que levam à conclusão de que uma das dificuldades apresentadas por esses sujeitos reside na Estratégia Busca de Ajuda Interpessoal. Embora os dados demonstrem que os participantes do Grupo 1 procuram auxílio dos professores e dos colegas, enquanto os do Grupo 2 buscam sanar suas dúvidas com colegas, as médias gerais para a categoria revelam que os estudantes de ambos os grupos apresentam pouca iniciativa nesse sentido.

Outro resultado evidente diz respeito à utilização da Estratégia Metacognitiva pelos estudantes do Grupo 1. De acordo com as médias das assertivas, um dos fatores que influenciam no bom rendimento desse grupo é a sua opção altamente frequente por ações relacionadas ao aprender a aprender. 


\section{Considerações finais}

Atualmente, a Física é encarada como uma das disciplinas mais exigentes, o que, muitas vezes, desmotiva os estudantes a estudarem os conceitos da área, tanto os que se julgam inteligentes/estudiosos quanto os que entendem não ter aptidão para a disciplina. Dentre os diversos fatores que podem influenciar essa reação por parte dos alunos está o modo pelo qual eles tentam se apropriar do conhecimento ao estudar os conteúdos associados a disciplina.

Isso ocorre, na maioria dos casos, porque os estudantes não encontram estratégias que os levem realmente a aprender os fenômenos físicos, tornando mecânico e pouco frutífero o estudo. Sendo assim, o presente trabalho buscou contribuir com as discussões relativas as diferenças entre as estratégias de aprendizagem utilizadas por estudantes com bom rendimento escolar em Física - constatado através de notas e da opinião do professor da disciplina - e as estratégias adotadas pelos que não obtêm o rendimento esperado. Identificadas tais estratégias, buscou-se verificar se elas representam influência no desempenho dos estudantes durante as aulas.

A pesquisa demonstrou que os participantes fazem uso de diferentes estratégias de aprendizagem no processo de ensino. No entanto, as ações relacionadas à Estratégia Busca de Ajuda Interpessoal são menos utilizadas pelos participantes, independentemente do grupo a que pertencem. Outro aspecto que chama a atenção no estudo realizado foi a diferença entre os resultados dos dois grupos em termos das Estratégias de Autorregulação, que são acompanhadas pelas Estratégias Metacognitivas. Tais estratégias referem-se a elementos que se aproximam entre si, especialmente em termos da capacidade de identificar suas próprias características e a partir disso regular, monitorar e avaliar a própria ação. Os resultados próximos assinalados por essas duas estratégias são indicativos da pertinência do instrumento utilizado, mas, especialmente, de que a utilização dos processos metacognitivos acompanhados dos autorregulatórios, são os diferenciais dos estudantes que apresentam melhores rendimentos em Física em comparação com os demais. Tal resultado vem ao encontro do anunciado por pesquisadores como Reif e Larkin (1991) e Malone (2008), entre outros, como mencionado na introdução deste texto.

Em termos mais gerais e associados a aprendizagem escolar, Gomes e Almeida (2016) mencionam estudos que mostraram que a potencialidade do uso das estratégias metacognitivas não se restringe a Física, mas representam uma característica que se estende a aprendizagem escolar de uma forma geral: "Os resultados mostraram que, além de um alto nível intelectual, os estudantes utilizavam com facilidade as estratégias metacognitivas descritas na literatura e mostraram autonomia na condução de sua aprendizagem" (p. 60).

Por fim, vale salientar que, evidentemente, há outros fatores que influenciam a aprendizagem escolar, como assinalado anteriormente em termos da postura e metodologia do professor, por exemplo. Entretanto, a forma como os alunos se estruturam para aprender, configura entre os fatores mais decisivos na aprendizagem e, por consequente, no sucesso escolar. Portanto, ao findar esse texto, indica-se a importância de que os professores considerem em seu fazer pedagógico o modo como os alunos aprendem e possam auxiliar, especialmente os que necessitam, a buscar alternativas de qualificação do seu processo de aprendizagem a partir da revisão e adoção de novas formas de aprender. 


\section{Referências}

ABBAD, Gardênia da Silva; MOURÃO, Luciana; MENESES, Pedro P. M.; ZERBINI, Thaís; BORGESANDRADE, Jairo Eduardo; VILLAS-BOAS, Raquel. Medidas de avaliação em treinamento, desenvolvimento e educação. Porto Alegre, RS: Artmed, 2012.

ASSMANN, Hugo. Reencantar a educação: rumo à sociedade aprendente. Petrópolis, RJ: Vozes, 1998.

BELTRAN, Jose Maria Martinez. La mediación en el proceso de aprendizaje. Madrid: Bruño, 1994.

BORUCHOVITCH, Evely. Aprender a aprender: propostas de intervenção em estratégias de aprendizagem. ETD - Educação Temática Digital, v. 8, n. 2, p. 156-167, 2007. DOI: 10.20396/etd.v8i2.651

BORUCHOVITCH, Evely. Autorregulação da aprendizagem: contribuições da psicologia educacional para a formação de professores. Psicologia Escolar e Educacional, v. 18, n. 3, p. 401-409, 2014. doi: 10.1590/2175-3539/2014/0183759

CAVENAGHI, Ana Raquel Abelha; BZUNECK, José Aloyseo. A motivação de alunos adolescentes enquanto desafio na formação do professor. In: CONGRESSO NACIONAL DE EDUCAÇÃO EDUCERE, 9, 2009; ENCONTRO SUL BRASILEIRO DE PSICOPEDAGOGIA, 3, 2009, Curitiba, PR. Anais... Curitiba, PR: PUCPR. p. 1479-1489.

DEMBO, Myron H. Applying educational psychology. New York: Longman Publishing Group, 1994.

DUTRA, Glênon; MARTINS, Maria Inês. A recuperação paralela no ensino de física: o que pensa o professor? Ensaio: Avaliação e Políticas Públicas em Educação, v. 20, n. 74, p. 135-164, 2012.

FIGUEIRA, Ana Paula Couceiro. Estratégias cognitivo/comportamentais de aprendizagem: problemática conceptual e outras rubricas. Revista Iberoamericana de Educación, v. 37, n. 6 (número especial), 2006. Disponível em: <http://www.rieoei.org/1130.htm>. Acesso em: 25 mar. 2015.

FLAVELL, John H.; MILLER, Patricia H.; MILLER, Scott A. Desenvolvimento cognitivo. Trad. Cláudia Dornelles. 3. ed. Porto Alegre: Artes Médicas Sul, 1999.

FONSECA, Vitor da. Importância das emoções na aprendizagem: uma abordagem neuropsicopedagógica. Revista Psicopedagogia, v. 33, n. 102, p. 365-384, 2016.

GARNER, Ruth; ALEXANDER, Patricia A. Metacognition: answered and unanswered questions. Educational Psychologist, v. 24, n. 2, p. 143-158, 1989.

Gil, Antonio Carlos. Como elaborar projetos de pesquisa. São Paulo, SP: Atlas, 2002.

Gil, Antonio Carlos. Métodos e técnicas de pesquisa social. São Paulo, SP: Atlas, 2008.

GOMES, Ana Silva Alves; ALMEIDA, Ana Cristina P. C. Letramento científico e consciência metacognitiva de grupos de professores em formação inicial e continuada: um estudo exploratório. Amazônia: Revista de Educação em Ciências e Matemática, v. 12, n. 24, p. 53-72, 2016.

GROSS, James J. Handbook of emotion regulation. 2. ed. London: The Guilford Press, 2013. 
IVANOWSKI, Márcia. O conteúdo de física no ensino médio e a desmotivação do aluno: um estudo de caso. 2005. 81 f. Dissertação (Mestrado em Educação e Cultura) - Universidade do Estado de Santa Catarina, Florianópolis, 2005.

KNÜPPE, Luciane. Motivação e desmotivação: desafio para as professoras do Ensino Fundamental. Educar em Revista, n. 27, p. 277-290, 2006. doi: 10.1590/S010440602006000100017

MALONE, Kathy L. Correlations among knowledge structures, force concept inventory, and problem-solving behaviors. Physical Review Special Topics - Physics Education Research, v. 4, n. 2, p. 020107-1-15, 2008.

MARTINS, Lara Barros; ZERBINI, Thaís. Escala de Estratégias de Aprendizagem: evidências de validade em contexto universitário híbrido. Psico-USF, v. 19, n. 2, p. 317-328, 2014. DOI: 10.1590/1413-82712014019002007

MONEREO, Carles. La enseñanza estratégica: enseñar para la autonomía. In: MONEREO, Carles. Ser estratégico y autónomo aprendiendo. Barcelona: Graó, 2001. p. 11-27.

PORTILHO, Evelise María Labatut. Aprendizaje universitario: un enfoque metacognitivo. 2003. 346 f. Tese (Doctorado en Educación) - Universidad Complutense de Madrid, Madrid, 2003.

POZO, Juan Ignácio. Más allá del cambio conceptual: el aprendizaje de la ciencia como cambio representacional. Enseñanza de las Ciencias, v. 17, n. 3, p. 513-520, 1999.

REIF, Frederick; LARKIN, Jill H. Cognition in scientific and everyday domains: comparison and learning implications. Journal of Research in Science Teaching, v. 28, n. 9, p. 733-760, 1991.

RIBEIRO, Célia. Metacognição: um apoio ao processo de aprendizagem. Psicologia: reflexão e crítica, v. 16, n. 1, p. 109-116, 2003. Disponível em:

<http://www.scielo.br/pdf/prc/v16n1/16802.pdf>. Acesso em: 18 maio 2017.

ROSA, Cleci Teresinha Werner da. A metacognição e as atividades experimentais no ensino de Física. 2011. 324 f. Tese (Doutorado em Educação Científica e Tecnológica) - Universidade Federal de Santa Catarina, Florianópolis, 2011.

ROSA, Cleci Teresinha Werner da. Metacognição no ensino de Física: da concepção à aplicação. Passo Fundo, RS: Editora da Universidade de Passo Fundo, 2014.

SILVA, Adelina Lopes da; SÁ, Isabel. Saber estudar e estudar para saber. Porto, Portugal: Porto Editora, 1997. (Coleção Ciências da Educação).

TAASOOBSHIRAZI, Gita; FARLEY, John. A multivariate model of physics problem solving. Learning and Individual Differences, v. 24, p. 53-62, abr. 2013. DOI: 10.1016/j.lindif.2012.05.001.

WARR, Peter; ALLAN, Catriona. Learning strategies and occupational training. International Review of Industrial and Organizational Psychology, v. 13, n. 1, p. 83-121, 1998.

WEINSTEIN, Clair E.; MAYER, Richard E. The teaching of learning strategies. In: WITTROCK, Merlin C. (Ed.). Handbook of research on teaching: a project of the research association. 3. ed. New York: MacMillan Publishing Company, 1986. p. 315-327.

ZERBINI, Thaís; ABBAD, Gardênia. Estratégias de aprendizagem em curso a distância: validação de uma escala. Psico-USF, v. 13, n. 2, p. 177-187, 2008. doi.org/10.1590/S141382712008000200005 . 